\title{
Personal Epistemology of University Students: Individual Profiles
}

\author{
Minna Kaartinen-Koutaniemi and Sari Lindblom-Ylänne \\ Institute of Behavioural Sciences, University of Helsinki, P.O. Box 3, 00014 Helsinki, Finland \\ Correspondence should be addressed to Minna Kaartinen-Koutaniemi, minna.kaartinen-koutaniemi@helsinki.fi
}

Received 24 January 2012; Revised 13 March 2012; Accepted 13 March 2012

Academic Editor: Jan Elen

Copyright ( 2012 M. Kaartinen-Koutaniemi and S. Lindblom-Ylänne. This is an open access article distributed under the Creative Commons Attribution License, which permits unrestricted use, distribution, and reproduction in any medium, provided the original work is properly cited.

\begin{abstract}
The aims of this study were to examine and compare the consistency of personal epistemology profiles among university students representing three academic disciplines. Student interview data $(N=87)$ were analyzed in order to reveal students' conceptions of knowledge, thinking, and reasoning. The individual answers were examined and rated on a scale from absolutist to evaluativist thinking. On the basis of the student answers, three personal epistemology profiles were identified from the data: (i) absolutist profiles; (ii) relativistic profiles; and (iii) evaluativist profiles consisting of the subgroups entitled "limited" and "sophisticated." The categorization of personal epistemology profiles was compared with background variables such as age, major subject, and study phase. The results indicated that the personal epistemology profiles varied significantly among students on the basis of the background variables. Explanations for the consistent and inconsistent personal epistemology profiles are discussed in more detail.
\end{abstract}

\section{Introduction}

1.1. Research on Personal Epistemology and Student Profiles. Personal epistemology, or beliefs that individuals hold about knowledge and knowing, has been examined during the past four decades. Since the pioneer work of Perry $[1,2]$, scholars have analyzed students' epistemic beliefs, defined as beliefs about the nature of knowledge and knowing, and the justification for these beliefs in higher education $[3,4]$. Furthermore, Perry's [1,2] developmental approach offered a stage theory of how students move from a dualist level toward more relativist and evaluativist levels of epistemological understanding. The main paradigmatic approaches of personal epistemology studies have been the subject of several critical reviews [3,5-7]. To summarize the history of this line of research, personal epistemology has mainly been explored by applying either quantitative Likert-type scales or qualitative interview settings. Previous studies on personal epistemology have revealed that the development of academic thinking and reasoning proceeds from dualistic to evaluativist thinking (see, e.g., $[3,4]$ for reviews).

However, the most recent reviews have challenged previous research on the development of personal epistemology. As Muis et al. [7] have argued, this development has been shown to be difficult to explore. In fact, when critically evaluated, Likert-type measurements and questionnaires have failed to indicate the development and growth of personal epistemology. Instead, understanding of the complexity of individual personal epistemology has been more reliably achieved with qualitative methods [3, 7-10]. Recent questions about personal epistemology, especially in educational psychology, concern the relation between epistemic beliefs, other cognitive processes, and achievements. The challenge has also been to reach a consensus on terminology, ontology, and dimensionality among researchers examining personal epistemology. In addition, researchers hold different views on the stable versus dynamic/changeable nature as well as on the context dependency of personal epistemology $[11,12]$.

Previous studies of students' personal epistemology profiles have mainly been quantitative. For example, Muis have examined relations between epistemic profiles, the regulation of cognition and problem solving in mathematics [13] and educational psychology course [14]. Her objective was to "examine a new methodology for measuring epistemic profiles-individuals' beliefs about how knowledge is derived and justified" ([13], page 179). Furthermore, the research questions were "Are there mean differences in selfreported and actual regulation of cognition and in problem 
solving performance as a function of epistemic profile?" ([14], page 33). Muis based her study on Royce's model of psychological epistemology and the psychoepistemological profile (PEP) inventory developed by Royce and Mos (see [13]). The PEP measures epistemological dimensions reflecting three different epistemic profiles: rationalism (conceptualizing), empiricism (perceiving), and metaphorism (symbolizing). The results of the study supported previous studies suggesting that epistemic beliefs are related to selfregulated learning and achievement. Furthermore, the results provided empirical evidence that students' approaches to problem solving were consistent with their performances in problem-solving tasks $[13,14]$.

Alexander and Murphy $[15,16]$ examined the profiles of educational psychology students by quantitative cluster analysis with the main aim of determining the nature, consistency, and malleability of student profiles. As a result, four student profiles were identified, entitled learning-oriented, strong-knowledge, effortful-processor, and nonstrategicreader clusters. The results revealed that the most successful students integrated their knowledge, interest and strategic abilities. Furthermore, there were two learning paths to successful learning outcomes. In the first, the students acquired and relied upon relevant knowledge, while in the second, the students combined knowledge with strong individual interest, and strategic effort $[15,16]$.

Bråten and Olaussen [17] followed Alexander's and Murphy's $[15,16]$ work by publishing the results of a longitudinal study of student profiles concerning changes in epistemological beliefs during the first and the second study year. The results, examined with cluster analysis, showed no disciplinary differences between student nurses and business administration students. In fact, the individual profiles were consistent, as students with high motivation held the most sophisticated epistemological beliefs about the nature of knowledge and knowledge acquisition [17].

Furthermore, Marra and Palmer [18] examined students' intellectual development on Perry's scale using both qualitative and quantitative research methods. Their main aim was to compare how study experiences affect the ability of students to think complexly about difficult problems. Students representing the opposite ends of the Perry scheme of intellectual development were compared. In particular, student profiles and students' educational experiences were examined to identify similarities and differences. As a result, the most significant aspects of students' experiences concerned the importance of their intellectual independence in teaching and learning, group work, problem solving, and the whole college experience [18].

1.2. Theoretical Framework. In order to promote research on students' personal epistemology profiles, the present study examined and compared the consistency of personal epistemology profiles among students representing three academic disciplines via qualitative interviews. Hofer and Pintrich [3] have illustrated the framework that describes four dimensions of personal epistemology: (a) the certainty of knowledge (the belief that knowledge is absolute and unchanging versus tentative and evolving), (b) the simplicity of knowledge (the belief that knowledge consists of isolated facts versus highly interrelated concepts), (c) the source of knowledge (the beliefs that knowledge is transmitted from an external authority versus actively constructed by individuals in interaction), and (d) the justification for knowing (through observation, authority, intuition versus research methods and acquisition of knowledge), (detailed definitions in parentheses by [19]). This framework has been created on the basis of literature review $[3,10]$ and several studies $[9,20,21]$. The interview questions of the present study were designed on the basis of the same framework and the underlying focus of questions concerning students' beliefs of knowledge and knowing. Furthermore, the aim was to demonstrate variation in students' responses to particular dimensions of personal epistemology such as the certainty of knowledge and justification for knowing. Human experience can be inconsistent and incoherent as well as consistent and coherent [22]. Furthermore, personal epistemology can be described along a continuum from less sophisticated to more sophisticated $[13,14,23,24]$. The profiles were also examined on the basis of these dimensions.

Since Hofer and Pitrich's model of four dimensions of personal epistemology, Kuhn and coworkers $[25,26]$ have empirically tested the major levels of epistemological understanding that were also originally indentified by Hofer and Pintrich. As Hofer [12] has summarized, research on developmental models suggests that "individuals move from a position of egocentric subjectivity, prior to the acquisition of theory of mind, through the objectivity of absolutism to the subjectivity of multiplism, with the integration of objectivity and subjectivity as the hallmark of evaluativism, a level achieved all too rarely" ([12], page 89). Kuhn [27] has created a framework of steps toward mature epistemological understanding that describes the levels of (a) absolutist (facts are correct or incorrect, knowledge is from an external source and certain but not directly accessible, assertions are compared to reality and either true or false), (b) multiplist/relativistic (knowledge consists not of facts but of opinions, knowledge is uncertain and generated by human minds), and (c) evaluativist (judgments are evaluated and compared according to criteria of argument, alternatives and evidence, knowledge is uncertain but susceptible to evaluation and generated by human minds, critical thinking promotes sound assertions and enhances understanding). We have adopted Kuhn's model to define and label the student profiles of the present study. However, we have modified the characteristics of the labels in more detail by applying a content-based qualitative approach to identify the profiles. To summarize, in this study, the profiles are meant to encompass how individual student's responses reflect his or her personal epistemology.

The criteria for analysing the students' profiles were derived from Hofer's four dimensions of personal epistemology, namely the certainty of knowledge and justification for knowing, determining the nature of epistemic thinking on the scale from subjectivity to evaluativism, consistency of the answers on scale from consistent and coherent, and the quality of the content on scale from less sophisticated 
to more sophisticated. The aim is to analyze the students as entire individual units and not as separate dimensions of the students' thinking.

1.3. Research Questions. The present study is part of a research project exploring the academic thinking and personal epistemology of university students. The aim of the project is to understand and promote students' research and academic skills as a central goal of academic studies at the research-intensive University of Helsinki. In two previous articles, we have examined the personal epistemology of psychology students in separate study phases, and the differences in personal epistemology among final-year psychology, theology and pharmacy students. Furthermore, personal epistemology has been explored as a phenomenon among student groups [28]. In this article, the individual answers of interviewed students are investigated in more detail. The main focus was on examining students' beliefs about the nature of knowledge and knowing as a representation of their personal epistemology.

The aims of this study were (a) to examine the personal epistemology profiles that were identified from semistructured interview data, (b) to compare the consistency of the personal epistemology profiles among three academic disciplines, and (c) to examine the personal epistemology profiles of psychology students across study phases.

\section{Methodology}

2.1. Participants and Academic Contexts. The three disciplines were selected to represent diverse academic domains with different learning environments and epistemological assumptions. However, the objectives of their curricula were similar, namely, to provide qualifications to work in specific professions, and the study environments were researchintensive. Thus, the disciplinary contexts represented different scientific backgrounds, for example, according to Biglan's scale [29]. Psychology and theology represent soft sciences, including both pure and applied research fields, and pharmacy represents hard-applied sciences [29-32]. The main semistructured interview data were collected from randomly-selected second-, fourth- and sixth-year psychology $(n=53)$ students. Moreover, final-year theology $(n=19)$ and pharmacy $(n=15)$ students were interviewed to collect additional data for comparison. Therefore, the total number of voluntary interviewees was 87 . The settings of the participants and their ages are summarized in Table 1. The final-year students of psychology and theology were relatively coeval, including several adult students, but the pharmacy students were on average younger.

Students in the sample were native-born Finns with Finnish as their first language. They had graduated from upper secondary education before their university studies (one exception). Universities in Finland have restricted entry to studies. Applicants are ranked according to their grades in the national matriculation examination, and a demanding entrance examination, which is arranged once a year. All students first take a Bachelor's degree (180 credits), and most of them go on to directly complete their Master's degree $(300 / 330$ credits). One credit is defined as in the European Credit Transfer System so it takes from five to six years on average to complete the Master's studies (for more detail, see [28]). The disciplines have curricula that provide qualifications to work in a particular profession, for instance, as a teacher, psychologist, priest, or pharmacist.

2.2. Interviews. In the semistructured interviews, the students were asked to express their individual perspective of the cognitive process of thinking, knowing, and reasoning. The open-ended questions focused on the sources and the nature of knowledge, the essential process of acquiring knowledge, students' views on preferences of learning environments, and self-reflection about their own competences and abilities. The interview settings were designed to encourage the interviewees to provide free and open responses. The individual interviews were designed to follow the example of Chan and Elliott [33], Palmer and Marra [34], and Hofer [21], who have emphasized the significance of qualitative data and have defined the main themes when exploring personal epistemology. In order to focus on beliefs concerning knowledge and knowing, the students were asked questions about how they would resolve a situation in which the sources of knowledge conflict, what sources of knowledge they trust, whether they remember an example of situation in which they had been critical of an idea, a justification, or a theory, and whether there is a difference between their academic and non-academic thinking. The interview questions were the following: How do you solve a situation if there are contradictory results on the same research topic? Tell an example of the situation when you have been critical towards a scientific idea, explanation, or theory? Do you consider the course books as reliable-please give arguments for your answer. What kind of thinking is required in your academic studies, especially in your major discipline? What kinds of skills and competences do you think you have to carry out research, for example, for your Master thesis? The primary questions were similar for all participants. In addition, the students were asked to explain, with examples, why they held certain beliefs and to elaborate on what they said. The interviews were recorded, transcribed verbatim, and the content analyzed with the ATLASti computer program.

2.3. Analyses. The interview data were qualitatively analyzed via content analysis to define student profiles. Additionally, the categorization of personal epistemology profiles was quantitatively compared with background variables such as age, major subject, and study phase. The quantitative cross-tabulations were performed with the SPSS computer program.

In order to define personal epistemology profiles, content analysis was performed in two stages. Firstly, the authors independently read the interviews and made notes on the essential aspects characterizing different personal epistemology profiles. The criteria for consistent or inconsistent absolutist and evaluativist profiles were derived from research on personal epistemology (e.g., $[1,3,10,25,27])$ and were based 
TABLE 1: Summary of interviewed students $(N=87)$.

\begin{tabular}{|c|c|c|c|c|c|c|c|c|c|c|c|c|}
\hline \multirow{3}{*}{ Age (years) } & \multicolumn{10}{|c|}{ Discipline and study year } & & \\
\hline & \multicolumn{2}{|c|}{$\begin{array}{c}\text { Psychology, } \\
\text { 2nd year }\end{array}$} & \multicolumn{2}{|c|}{$\begin{array}{c}\text { Psychology, } \\
\text { 4th year }\end{array}$} & \multicolumn{2}{|c|}{$\begin{array}{l}\text { Psycholog, } \\
\text { 6th year }\end{array}$} & \multicolumn{2}{|c|}{$\begin{array}{l}\text { Theology, } \\
\text { 6th year }\end{array}$} & \multicolumn{2}{|c|}{$\begin{array}{l}\text { Pharmacy, } \\
\text { 5th year }\end{array}$} & \multicolumn{2}{|c|}{ Total } \\
\hline & $n$ & $\%$ & $n$ & $\%$ & $n$ & $\%$ & $n$ & $\%$ & $n$ & $\%$ & $N$ & $\%$ \\
\hline $19-23$ & 13 & 76.5 & 9 & 50 & 0 & 0 & 1 & 5 & 9 & 60 & 32 & 37 \\
\hline $24-25$ & 1 & 6 & 6 & 33 & 8 & 44 & 8 & 42 & 5 & 33 & 28 & 32 \\
\hline over 26 & 3 & 17.5 & 3 & 17 & 10 & 56 & 10 & 53 & 1 & 7 & 27 & 31 \\
\hline Total & 17 & 100 & 18 & 100 & 18 & 100 & 19 & 100 & 15 & 100 & 87 & 100 \\
\hline
\end{tabular}

on the versatility of the answers characterizing views on the sources and the nature of knowledge and the essential process of acquiring knowledge. The sorting of students began with the answers categorized as systematically characterizing consistent absolutist or evaluativist thinking. Next, the authors compared their definitions and discussed the answers. Most of the students $(n=67 ; 77 \%)$ were similarly categorized in the groups with systematically absolutist $(n=26)$ or evaluativist $(n=41)$ profiles.

However, the remaining student answers ( $n=20 ; 23 \%)$ were more difficult to categorize as the students' responses revealed inadequate skills to articulate their thinking. In addition, these remaining answers were partly frugal and inexact despite the fact that clarifying questions were asked from the students. As a consequence, the authors examined these 20 uncategorized answers in detail together.

Firstly, the authors were able to diagnose 10 profiles, which included both absolutist and evaluativist elements. These profiles were entitled as inconsistent profiles. Secondly, the 10 remaining answers seem to systematically reflect evaluativist conceptions, but they were not as sophisticated as those representing the evaluativist personal epistemology. Therefore, the authors decided to divide the evaluativist personal epistemology profiles into two subgroups: limited and sophisticated. Thus, the remaining 10 profiles were categorized as representing a limited evaluativist profile $(n=$ 10). The strength of the approach taken in the present study was that the individual answers were not forced into a predetermined categorization, but instead, the profile groups were formed to reflect variation in students answers.

Finally, the interviews categorized in the same profile groups were read through in order to verify the consistent alignment of categorizations. As a result, three main personal epistemology profiles were confirmed: (a) absolutist profiles; (b) relativistic profiles; (c) evaluativist profiles consisting of two subgroups entitled "limited" and "sophisticated." The characteristics of these profiles are explained in more detail in the next chapter.

\section{Results}

3.1. Personal Epistemology Profiles. The main themes of the interview data were the criteria that students used to evaluate the quality and reliability of knowledge. Furthermore, the students described their experiences of requirements for thinking set by their academic context. According to the student answers for the themes mentioned above, the three personal epistemology profiles were identified from the data. These profile groups are next described in more detail.

The group of absolutist personal epistemology profiles comprised 26 students. Their answers characterized unreflective thinking and the students listed criteria to evaluate knowledge without justifications. The answers revealed subjective thinking and when asked for more detailed answers, the students could not explain their views. Instead, they relied on authorities, for example, teachers or literature. They held a conception of knowledge that underlines the importance of transmitted knowledge, for example, by teachers. Some students even held misconceptions about research methods or the reliability of knowledge. The following quotation was typical for students with absolutist personal epistemology profiles:

I appreciate the knowledge of well-known authorities, such as academic researchers and professors, over the other sources of information. I think academic knowledge is some kind of objective, I mean, the references are listed and the writer has used the academic terms and language. (2nd year Psychology Student number 42.)

The answers of students characterizing relativistic personal epistemology profiles included inconsistent details on the scale from absolutist to evaluativist thinking. In general, ten students described their criteria in evaluating the validity of knowledge with relativistic views. By contrast, their practical examples or explanations were less relativistic. The answers revealed the conflict between the knowledge and skills of the students, as the next quotation shows:

During the quantitative method course I decided not to believe in any scientific results. I mean, it is really difficult to interpret results, especially between contradictory facts and knowledge. I try to see the big picture and context of the studies as well as the certain principals of valid research. I mean tests, analysis, and the justification of results. But I really can't judge the reliability and validity of studies by myself, so I usually believe what is written and published. (5th year Pharmacy Student number 98.) 
TABLE 2: Cross-tabulation of personal epistemology profiles and student ages $(N=87)$.

\begin{tabular}{|c|c|c|c|c|c|c|c|c|c|}
\hline \multirow{2}{*}{$\begin{array}{l}\text { Personal } \\
\text { epistemology profiles }\end{array}$} & & \multicolumn{2}{|c|}{ 19-23 years } & \multicolumn{2}{|c|}{$24-25$ years } & \multicolumn{2}{|c|}{ over 26 years } & \multicolumn{2}{|c|}{ Total } \\
\hline & & $n$ & $\%$ & $n$ & $\%$ & $n$ & $\%$ & $N$ & $\%$ \\
\hline Absolutist & & 13 & 40.5 & 8 & 28.5 & 5 & 19 & 26 & 30 \\
\hline Relativistic & & 6 & 19 & 1 & 3.5 & 3 & 11 & 10 & 11.5 \\
\hline Evaluativist & Total & 13 & 40.5 & 19 & 68 & 19 & 70 & 51 & 58.5 \\
\hline Limited & & 1 & 3 & 2 & 7 & 7 & 26 & 10 & 11.5 \\
\hline Sophisticated & & 12 & 37.5 & 17 & 61 & 12 & 44 & 41 & 47 \\
\hline & Total & 32 & 100 & 28 & 100 & 27 & 100 & 87 & 100 \\
\hline
\end{tabular}

The evaluativist profiles were categorized into two subgroups: limited and sophisticated personal epistemology profiles. Ten students were categorized in the group of limited evaluativist personal epistemology profiles. They answered consistently, implementing evaluativist thinking, but their answers were brief. If the interviewer asked them to specify their answers, the students repeated the same details or did not deepen the replies. The following example illustrates the profiles:

When I find contradictory results on the same topic, it actually confirms my idea of uncertainty of the research. I've a critical attitude to everything. I usually first check the data and publication year of the study. I have learnt a critical attitude towards knowledge because the research and methodology studies are really emphasized in our curriculum at the Department of Psychology. (4th year Psychology Student number 76.)

The group characterizing sophisticated evaluativist personal epistemology profiles comprised 41 students. Their answers were analytical or reflective. Furthermore, the more sophisticated answers showed alignment in students' academic knowledge, skills, and practices. The students with sophisticated evaluativist personal epistemology profiles justified their answers with practical examples or versatile arguments. They integrated information from multiple sources and described critical knowledge acquisition processing. The next example is representative of the students with an evaluativist personal epistemology profile:

First I check the approach of the study or the authors. I check the theoretical framework to be aware of the preconceptions of the authors so that I understand the context and source of the knowledge. It's important to follow the argumentation and the documented references. The process of research must be described from research questions to the results. I prefer research that includes deductive and inductive reasoning. (6th year Theology Student number 110.)

3.2. Comparison of the Personal Epistemology Profile Groups. The categorization of personal epistemology profiles was compared with background variables such as age, major subject, and study phase. Students were distributed between three approximately equal-size age groups, that is, students aged 19-23, 24-25, and over 26 years. The cross-tabulation between personal epistemology profiles and age was statistically significant $\left[\chi^{2}(6, N=87)=14.49, P=0.03\right]$. The students aged from 19 to 23 years were mainly categorized as absolutist or relativistic personal epistemology profile groups and the students over 24 years old, with some exceptions, were mostly characterized as having evaluativist personal epistemology profiles. The number of students with absolutist personal epistemology profiles was higher among younger than older age groups. The students with evaluativist personal epistemology profiles were least frequent in the youngest age group but were rather equal in number in two other age groups. The students belonging to the relativistic personal epistemology profile group were most common in the youngest and oldest age groups and the least in the middle age group. The results of the cross-tabulation between personal epistemology profiles and student age groups are summarized in Table 2 .

Furthermore, the cross-tabulations were used to explore the personal epistemology profiles of psychology students in separate study phases as well as the final-year students of the three disciplines. Psychology students $\left[\chi^{2}(6, n=\right.$ $53)=12.95, P=0.04]$ and final-year students of the three disciplines $\left[\chi^{2}(6, n=52)=12.73, P=0.05\right]$ belonged significantly more often to the evaluativist personal epistemology profile group that the other students. The psychology students already mostly belonged to the evaluativist personal epistemology profile groups in their fourth study year. Few students were categorized in absolutist or relativistic profile groups, as revealed in Table 3.

The differences between students from the three disciplines were examined in more detail among the finalyear students. The sixth-year psychology students were categorized significantly more often as having evaluativist personal epistemology profiles than the final-study year theology, and pharmacy students. Similarly, the number of theology and pharmacy students with absolutist personal epistemology profiles differed from that of psychology students. The frequency of relativistic profiles was rather similar among students from all three disciplines. The comparison is displayed in more detail in Table 4. 
TABLE 3: Cross-tabulation of personal epistemology profiles of psychology students $(N=53)$.

\begin{tabular}{|c|c|c|c|c|c|c|c|c|c|}
\hline \multirow{3}{*}{$\begin{array}{l}\text { Personal } \\
\text { epistemology profiles }\end{array}$} & & \multicolumn{6}{|c|}{ Psychology students } & & \\
\hline & & \multicolumn{2}{|c|}{ 2nd year } & \multicolumn{2}{|c|}{4 th year } & \multicolumn{2}{|c|}{ 6th year } & \multicolumn{2}{|c|}{ Total } \\
\hline & & $n$ & $\%$ & $n$ & $\%$ & $n$ & $\%$ & $N$ & $\%$ \\
\hline Absolutist & & 8 & 47 & 2 & 11 & 1 & 6 & 11 & 21 \\
\hline Relativistic & & 1 & 6 & 2 & 11 & 2 & 11 & 5 & 9 \\
\hline Evaluativist & Total & 8 & 47 & 14 & 78 & 15 & 83 & 37 & 70 \\
\hline Limited & & 2 & 12 & 1 & 6 & 4 & 22 & 7 & 13 \\
\hline \multirow[t]{2}{*}{ Sophisticated } & & 6 & 35 & 13 & 72 & 11 & 61 & 30 & 57 \\
\hline & Total & 17 & 100 & 18 & 100 & 18 & 100 & 53 & 100 \\
\hline
\end{tabular}

TABLE 4: Cross-tabulation of personal epistemology profiles of final-year students $(N=52)$.

\begin{tabular}{|c|c|c|c|c|c|c|c|c|c|}
\hline \multirow{3}{*}{$\begin{array}{l}\text { Personal } \\
\text { epistemology profiles }\end{array}$} & & \multicolumn{6}{|c|}{ Final-year students } & \multirow{2}{*}{\multicolumn{2}{|c|}{ Total }} \\
\hline & & \multicolumn{2}{|c|}{ Psychology } & \multicolumn{2}{|c|}{ Theology } & \multicolumn{2}{|c|}{ Pharmacy } & & \\
\hline & & $n$ & $\%$ & $n$ & $\%$ & $n$ & $\%$ & $N$ & $\%$ \\
\hline Absolutist & & 1 & 6 & 7 & 37 & 8 & 53 & 16 & 31 \\
\hline Relativistic & & 2 & 11 & 2 & 10.5 & 3 & 20 & 7 & 13.5 \\
\hline Evaluativist & Total & 15 & 83 & 10 & 52.5 & 4 & 27 & 29 & 55.5 \\
\hline Limited & & 4 & 22 & 3 & 15.5 & 0 & 0 & 7 & 13.5 \\
\hline Sophisticated & & 11 & 61 & 7 & 37 & 4 & 27 & 22 & 42 \\
\hline & Total & 18 & 100 & 19 & 100 & 15 & 100 & 52 & 100 \\
\hline
\end{tabular}

\section{Discussion}

4.1. Individual Profiles and Personal Epistemology. The results of this study clearly demonstrated that personal epistemology profiles varied between students in different age groups, study phases and disciplines. Furthermore, there was variation in student personal epistemology profiles particularly concerning the justification for knowing, which was examined and rated on a scale from absolutist to evaluativist epistemological understanding. The main themes of the interview data were the criteria that students used to evaluate the quality and reliability of knowledge. Furthermore, the students described their experiences of requirements for thinking set by their academic context.

Personal epistemology and individual student profiles have mainly been explored by applying quantitative methods [13-18]. Nevertheless, Marra and Palmer [18] have interestingly reported similar findings. They argued that senioryear students with a relativistic profile on Perry's scheme of intellectual development represented the required skills and abilities of academic students, in other words, the ability to construct knowledge, to solve ill-structured problems, and to hold relative and contextual view of knowledge. In contrast, students with dualistic profiles appreciated student-centered learning experiences, but they still relied on authority and held a conception of knowledge. In addition, they had problems with ill-structured problem-solving tasks and the contextual view of knowledge [18]. The evaluativist and absolutist personal epistemology profiles observed in the present study characterize similar contrasts and contents.

Differences between epistemological profile groups may have several causes. For example, it is possible that the students belonging to the relativistic personal epistemology profile group were interviewed in the middle of a developmental process. In other words, the profiles were possibly diagnosed as relativistic because the students were going through a developmental process from absolutist to evaluativist thinking. For instance, the psychology students with relativistic profiles described the criteria of research in depth, but they were unable to explain their actions as active researchers. Furthermore, the theology students mentioned the difficulty or insecurity in practically applying their knowledge of research. Instead, they needed support from their supervisors or from other students. In addition, the pharmacy students categorized into the relativistic profile group underlined on the one hand the importance of the practical pharmaceutical skills required by the disciplinary environment and future employees. On the other hand, these students relied on knowledge of science. The majority of pharmacy students considered knowledge as scientifically verifiable and saw individual thinking and learning as comprising the absorption of that information.

In research into personal epistemology, students' epistemic awareness has been shown to develop during their studies [35]. An interesting aspect of our interview data was the exceptional results of the pharmacy students. In the comparison between age groups, disciplinary student groups and personal epistemology profiles, most of the students over 24 years old, were categorized into the evaluativist profile group. However, the final-year pharmacy students were on average younger that the psychology and theology students and over a half of them were categorized into the absolutist personal epistemology profile group. One interpretation might be that the disciplinary environment of the Faculty 
of Pharmacy combined with the young age of the students did not increase the epistemic awareness or develop the personal epistemology of the students during their academic studies. By contrast, the disciplinary environment of psychology students seemed to demand a evaluativist personal epistemology from the beginning of their studies, as nearly half of the students in the youngest age group and almost all the final-year psychology students were categorized as having a evaluativist personal epistemology profile. By comparison, the final-year theology students were rather similar in age to the psychology students but on the scale between absolutist and evaluativist personal epistemology profiles; over one third of students were still categorized into the absolutist profile group. Consequently, the disciplinary environment of theology did not challenge all the students develop an evaluativist personal epistemology profile.

To summarize, the results of the present study showed that individual student answers could be categorized into both consistent and inconsistent personal epistemology profiles. The qualitative methodological approach applied here to examine the interview data revealed new perspectives on personal epistemology, particularly at the individual student level. This study interestingly completes our previous reports exploring the general elements comprising personal epistemology. The aim was to capture students' insight into the congruence of their personal epistemology in a specific situation and time. The new approach also confirmed Hofer's statement of the importance of qualitative interview methods: "By listening to individuals' responses to particular questions and determining whether their interpretation of questions is consistent with intended meaning, researchers can gain more measurement precision" ([35], page 70). To confirm this, the content analyses showed good reliability as our interrater agreement (94\%) was high. The authors negotiated the categorization of consistent but limited evaluativist answers and relativistic answers. In particular, the rare and inconsistent answers were analyzed and interpreted together $(n=4)$. Overall, the agreement over categorization and reliability of analysis was high.

4.2. Theoretical and Educational Significance. The present study has provided a unique picture of individual personal epistemology profiles among psychology, theology, and pharmacy students. Furthermore, the study has educational significance, as the results can be utilized by teachers in university pedagogy courses. The results imply that teacher guidance in supporting the development of expertise in students, especially in supervising Bachelor's and Master's theses, is important. When teachers are aware of the role of personal epistemology in successful academic achievement, they are likely to be more interested in challenging their students to discuss disciplinary questions of epistemology. Teachers should teach students to evaluate knowledge, coordinate evidence, and make judgments about claims of truth as well as disciplinary knowledge and methods of knowing $[12,35]$. Therefore, in order to promote the development of personal epistemology in students, teachers should be encouraged to apply argumentative debate, cooperative learning, practical research assignments, and reflection in their teaching.

\section{Acknowledgments}

The authors are grateful to colleagues for helpful comments on a draft of this article, and to the students for participation. The first author was financially supported by a scholarship from the Finnish Cultural Foundation, and the University of Helsinki Funds.

\section{References}

[1] W. G. Perry Jr, Forms of Intellectual and Ethical Development in the College Years: A Scheme, Holt, Rinehart and Winston, New York, NY, USA, 1970.

[2] W. G. Perry Jr., "Foreword," in Understanding Student Learning, N. Entwistle and P. Ramsden, Eds., pp. 1-8, Groom Helm, London, UK, 1983.

[3] B. K. Hofer and P. R. Pintrich, "The development of epistemological theories: beliefs about knowledge and knowing and their relation to learning," Review of Educational Research, vol. 67, no. 1, pp. 88-140, 1997.

[4] B. K. Hofer and P. R. Pintrich, Eds., Personal Epistemology: The Psychology of Beliefs about Knowledge and Knowing, Lawrence Erlbaum Associates, Mahwah, NJ, USA, 1st edition, 2002.

[5] M. M. Buehl and P. A. Alexander, "Beliefs about academic knowledge," Educational Psychology Review, vol. 13, no. 4, pp. 385-418, 2001.

[6] B. K. Hofer, "Introduction: paradigmatic approaches to personal epistemology," Educational Psychologist, vol. 39, no. 1, pp. 1-3, 2004.

[7] K. R. Muis, L. D. Bendixen, and F. C. Haerle, "Domaingenerality and domain-specificity in personal epistemology research: philosophical and empirical reflections in the development of a theoretical framework," Educational Psychology Review, vol. 18, no. 1, pp. 3-54, 2006.

[8] L. D. Bendixen and D. C. Rule, "An integrative approach to personal epistemology: a guiding model," Educational Psychologist, vol. 39, no. 1, pp. 69-80, 2004.

[9] B. K. Hofer, "Epistemological understanding as a metacognitive process: thinking aloud during online searching," Educational Psychologist, vol. 39, no. 1, pp. 43-55, 2004.

[10] P. R. Pintrich, "Future challenges and directions for theory and research on personal epistemology," in Personal Epistemology: The Psychology of Beliefs about Knowledge and Knowing, B. K. Hofer and P. R. Pintrich, Eds., pp. 389-414, Lawrence Erlbaum Associates, Mahwah, NJ, USA, 1st edition, 2002.

[11] B. K. Hofer and G. M. Sinatra, "Epistemology, metacognition, and self-regulation: musings on an emerging field," Metacognition and Learning, vol. 5, no. 1, pp. 113-120, 2010.

[12] B. K. Hofer, "Domain specificity of personal epistemology: resolved questions, persistent issues, new models," International Journal of Educational Research, vol. 45, no. 1-2, pp. 8595, 2006.

[13] K. R. Muis, "Epistemic profiles and self-regulated learning: examining relations in the context of mathematics problem solving," Contemporary Educational Psychology, vol. 33, no. 2, pp. 177-208, 2008.

[14] K. Muis and G. Franco, "Epistemic profiles and metacognition: support for the consistency hypothesis," Metacognition and Learning, vol. 5, no. 1, pp. 27-45, 2010. 
[15] P. A. Alexander and P. K. Murphy, "Profiling the differences in students' knowledge, interest, and strategic processing," Journal of Educational Psychology, vol. 90, no. 3, pp. 435-447, 1998.

[16] P. A. Alexander and K. Murphy, "Learner profiles: valuing individual differences within classroom communities," in Learning and Individual Differences: Process, Trait, and Content Determinants, P. C. Kyllonen and R. D. Roberts, Eds., pp. 413436, American Psychological Association, Washington, DC, USA, 2nd edition, 2000.

[17] I. Bråten and B. S. Olaussen, "Profiling individual differences in student motivation: a longitudinal cluster-analytic study in different academic contexts," Contemporary Educational Psychology, vol. 30, no. 3, pp. 359-396, 2005.

[18] R. Marra and B. Palmer, "Encouraging intellectual growth: senior college student profiles," Journal of Adult Development, vol. 11, no. 2, pp. 111-122, 2004.

[19] H. I. Strømsø, I. Bråten, and M. S. Samuelstuen, "Dimensions of topic-specific epistemological beliefs as predictors of multiple text understanding," Learning and Instruction, vol. 18, no. 6, pp. 513-527, 2008.

[20] B. K. Hofer, "Dimensionality and disciplinary differences in personal epistemology," Contemporary Educational Psychology, vol. 25, no. 4, pp. 378-405, 2000.

[21] B. K. Hofer, "Exploring the dimensions of personal epistemology in differing classroom contexts: student interpretations during the first year of college," Contemporary Educational Psychology, vol. 29, no. 2, pp. 129-163, 2004.

[22] M. Freeman, K. deMarrais, J. Preissle, K. Roulston, and E. A. St. Pierre, "Standards of evidence in qualitative research: an incitement to discourse," Educational Researcher, vol. 36, no. 1, pp. 25-32, 2007.

[23] P. K. Murphy and L. Mason, "Changing knowledge and beliefs," in Handbook of Educational Psychology, P. A. Alexander and P. H. Winne, Eds., pp. 305-324, Lawrence Erlbaum Associates, Mahwah, NJ, USA, 2006.

[24] G. M. Sinatra and P. R. Pintrich, "The role of intentions in conceptual change learning," in Intentional Conceptual Change, G. M. Sinatra and P. R. Pintrich, Eds., pp. 1-18, Lawrence Erlbaum Associates, Mahwah, NJ, USA, 2003.

[25] D. Kuhn, R. Cheney, and M. Weinstock, "The development of epistemological understanding," Cognitive Development, vol. 15, no. 3, pp. 309-328, 2000.

[26] D. Kuhn and M. Weinstock, "What is epistemological thinking and why does it matter?" in Personal Epistemology: The Psychology of Beliefs about Knowledge and Knowing, B. K. Hofer and P. R. Pintrich, Eds., pp. 121-144, Lawrence Erlbaum Associates, Mahwah, NJ, USA, 1st edition, 2002.

[27] D. Kuhn, Education for Thinking, Harvard University Press, Cambridge, Mass, USA, 2005.

[28] M. Kaartinen-Koutaniemi and S. Lindblom-Ylänne, "Personal epistemology of psychology, theology and pharmacy students: a comparative study," Studies in Higher Education, vol. 33, no. 2, pp. 179-191, 2008.

[29] A. Biglan, "Relationships between subject matter characteristics and the structure and output of university departments," Journal of Applied Psychology, vol. 57, no. 3, pp. 204-213, 1973.

[30] T. Becher and P. R. Trowley, Academic Tribes and Territories: Intellectual Enquire and the Culture of Disciplines, SRHE and Open University Press, Buckingham, UK, 2nd edition, 2001.

[31] J. G. Donald, Learning to Think: Disciplinary Perspectives, Jossey-Bass Publishers, San Francisco, Calif, USA, 2002.
[32] R. Neumann, S. Parry, and T. Becher, "Teaching and learning in their disciplinary contexts: a conceptual analysis," Studies in Higher Education, vol. 27, no. 4, pp. 405-417, 2002.

[33] K. W. Chan and R. G. Elliott, "Exploratory study of Hong Kong teacher education students' epistemological beliefs: cultural perspectives and implications on beliefs research," Contemporary Educational Psychology, vol. 27, no. 3, pp. 392414, 2002.

[34] B. Palmer and R. M. Marra, "College student epistemological perspectives across knowledge domains: a proposed grounded theory," Higher Education, vol. 47, no. 3, pp. 311-335, 2004.

[35] B. K. Hofer, "Beliefs about knowledge and knowing: integrating domain specificity and domain generality: a response to Muis, Bendixen, and Haerle (2006)," Educational Psychology Review, vol. 18, no. 1, pp. 67-76, 2006. 


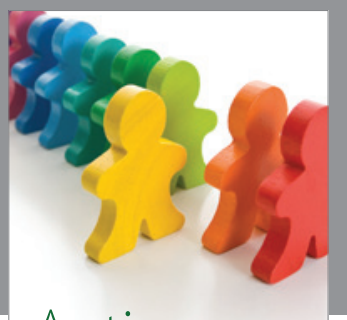

Autism

Research and Treatment
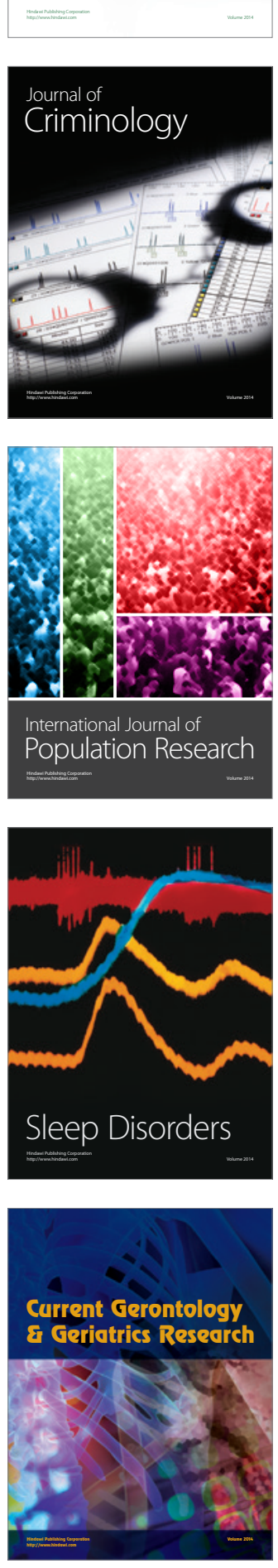
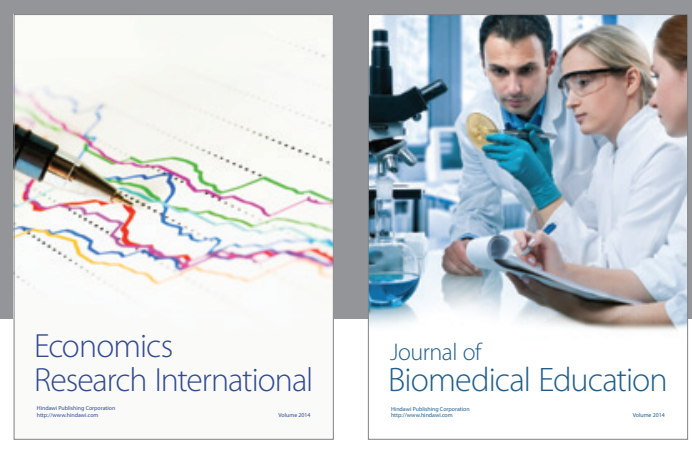

Journal of

Biomedical Education

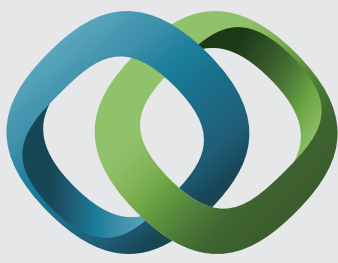

\section{Hindawi}

Submit your manuscripts at

http://www.hindawi.com
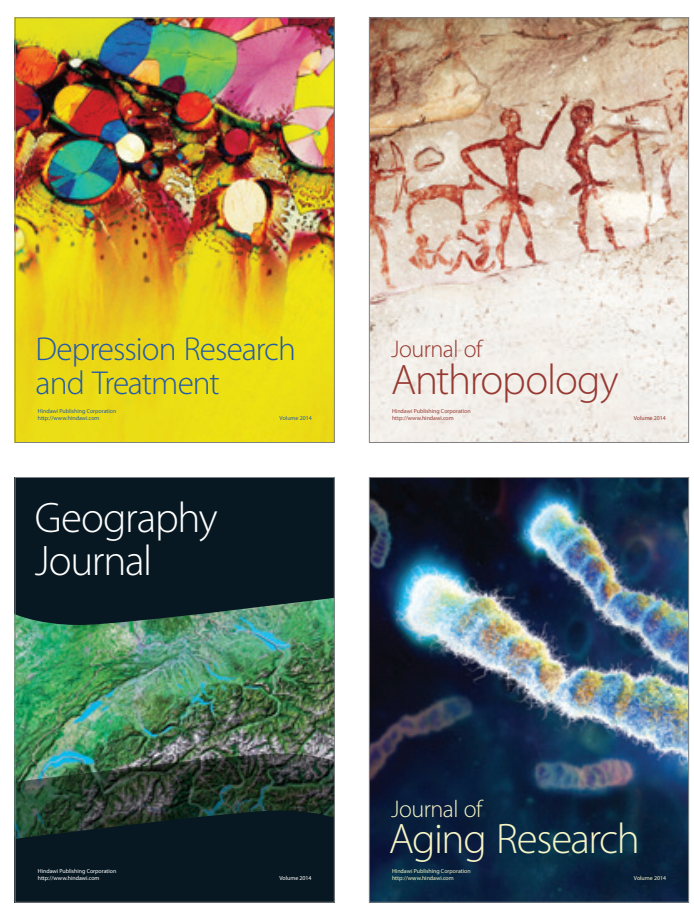

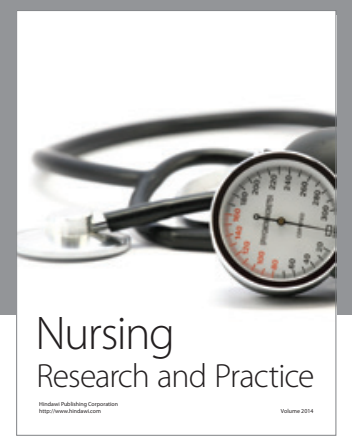

Nursing

Research and Practice

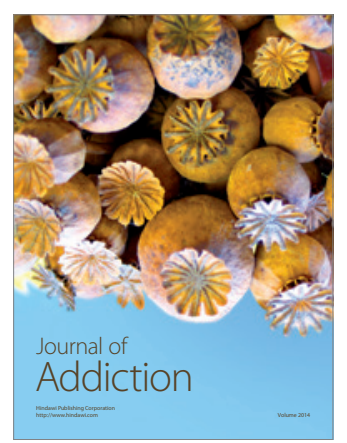

Child Development

Research

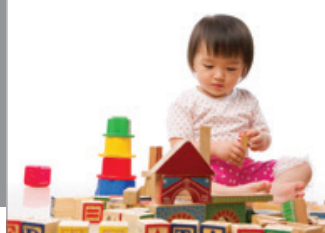

迥
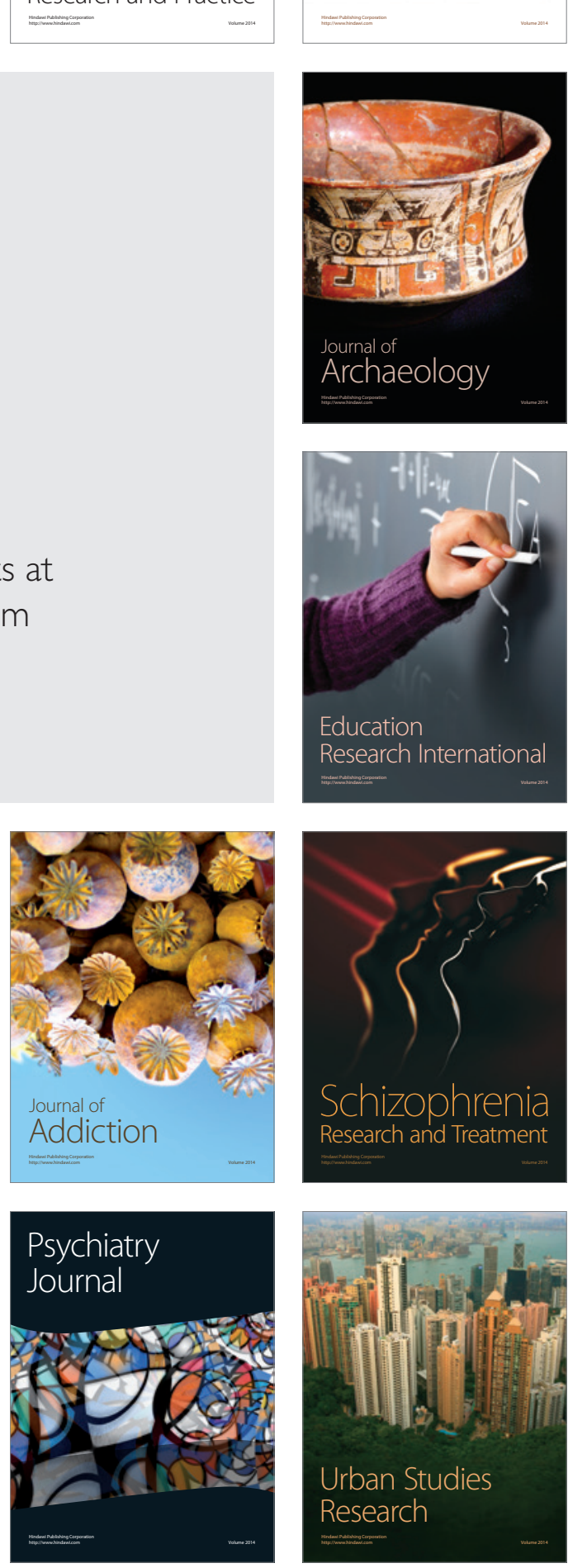